\title{
TRADICIÓN VASCA Y FEMINISMO EN «LA DAMA DE AMBOTO», DE GERTRUDIS GÓMEZ DE AVELLANEDA
}

\author{
Marcelo UrRalburu \\ Universitat de Barcelona \\ marcelo.iraultza@gmail.com \\ Berta Guerrero Almagro \\ Universidad Católica San Antonio de Murcia \\ aobaguo@gmail.com
}

Recibido: 20-02-2020

Aceptado: 15-04-2021

(c) (1)

RESUMEN

En el siguiente trabajo realizamos un análisis literario de la leyenda vasca «La dama de Amboto", de la cubana Gertrudis Gómez de Avellaneda, escrito durante los veranos de 1858 y 1859 en su visita a esta región española. De esta manera, atendemos a aspectos históricos y literarios para comprender el pensamiento feminista que se trasluce en la obra, por ejemplo, en su diálogo con las fervorosas lecturas que de Jean-Jacques Rousseau haría la autora a lo largo de su trayectoria literaria, y la presencia de numerosos mitos folclóricos vascos y clásicos que perviven en este texto. Desde nuestro punto de vista, el texto presentaría una imbricada construcción de lo fantástico como vehículo de su discurso feminista que encontraría su complemento perfecto en la tradición matriarcal de la Mari, diosa que habitaría en las montañas según la mitología vasca.

Palabras clave: Gómez de Avellaneda; feminismo; Romanticismo; leyenda; cultura vasca.. 


\section{BASQUE TRADITION AND FEMINISM IN «LA DAMA DE AMBOTO», BY GERTRU- DIS GÓMEZ DE AVELLANEDA}

ABSTRACT

In the following work we carry out a literary analysis of the Basque legend «La dama de Amboto», by Cuban Gertrudis Gómez de Avellaneda, written during the summers of 1858 and 1859 during her visit to this Spanish region. In this way, we examine historical and literary aspects to understand the feminist thought that transpires in her short story, for example, in its dialogue with the fervent readings of Jean-Jacques Rousseau's works that the author will do throughout her literary career, and the presence of several Basque and classical folk myths that survive in her text. From our point of view, the short story shows an imbricated construction of the fantastic as a vehicle of her feminist discourse that matches the matriarchal tradition of Mari, a goddess who would inhabit the mountains according to Basque mythology.

KEY-WORDS: Gómez de Avellaneda; feminism; Romanticism; legend; Basque culture.

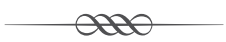

\section{INTRODUCCIÓN}

Los veranos de 1858 y 1859, la escritora hispano-cubana Gertrudis Gómez de Avellaneda (1814-1873) viajó a los Pirineos junto a su segundo esposo, Domingo Verdugo y Massieu. Como ha señalado Teodosio Fernández en «De pasiones imaginarias: la narrativa de Gertrudis Gómez de Avellaneda» (2014), de tales estancias extrae la temática para la escritura de los siguientes textos: «La bella Toda y Los doce jabalíes. Dos tradiciones ${ }^{1}$ de la Plaza del Mercado de Bilbao», «La dama de Amboto. Tradición vasca», ${ }^{2}$ «La flor del ángel. Tradición vascongada» y «La ondina del lago azul. Recuerdo de mi última excursión por los Pirineos» (2014: 8). En dichos títulos, Gómez de Avellaneda hace

1 Apunta Ángeles Ezama Gil que Gómez de Avellaneda emplea el término tradición frente al de leyen$d a$ «sobre todo cuando estas narraciones aparecen insertas en los relatos de viaje, tratando de ilustrar el carácter y costumbres de los pueblos recorridos mediante la relación de historias profundamente enraizadas en ellos» (2011: 335).

2 Las fechas de estos viajes resultan cruciales para remarcar un aspecto desatendido por la crítica focalizada en el mito de La dama de Amboto. Estudiosos como Jon Mentxakatorre Odriozola (2017: 16) señalan que el primer relato conocido de Mari es recogido por Barandiarán en 1920; Gómez de Avellaneda, sin embargo, transcribe la leyenda con anterioridad. 
gala de su virtuosismo: la variedad técnica al introducir cada uno de los argumentos convierte esta especie de ciclo en una exhibición de su arte. Si «La bella Toda y Los doce jabalíes» y «La ondina del lago azul» aparecen precedidos por las circunstancias biográficas de la escritora y se ponen en boca de sendos guías locales ${ }^{3}$ y si «La flor del ángel» comienza directamente con un narrador en tercera persona — profundamente verosímil al reconocer su insuficiencia- ${ }^{4}$ "La dama de Amboto» arranca interpelando al lector con una captatio benevolentiae:

¿Conocéis, queridos lectores, las pintorescas Provincias Vascongadas? Y si tenéis esa dicha, ¿recordáis la elevadísima peña llamada Amboto, que sirve de corona a la montaña de Echaguen? ¡Oh! de seguro os llamaría la atención esa singularidad de tener la cima un nombre diferente al de la montaña de que forma parte. Pues bien, yo voy a contaros la dramática historia que prestó fundamento a la mencionada rareza (Gómez de Avellaneda, 2008d: 149).

Un entorno natural — con peñas y montañas- envuelto por un halo de misterio y dramatismo. El marco resulta idóneo para apresar la atención de Gómez de Avellaneda, inclinada a la sublimidad romántica. La introducción de la leyenda continúa con la reiteración del procedimiento empleado en «La flor del ángel», de modo que Gómez de Avellaneda se gana definitivamente la confianza del receptor al introducir la incertidumbre temporal: «Sabed que existía en aquella altura, hace ya mucho tiempo — la tradición no determina más- un soberbio castillo, perteneciente a la ilustre familia de los Urracas...» (2008d: 149). La leyenda, grosso modo, relata el fratricidio cometido por María, primogénita de la familia de los Urraca, durante una jornada de caza. Tras el falleci-

3 «La bella Toda y Los doce jabalíes» se inicia así: «En el verano de 1858 pasé con mi marido algunos días en la limpia y bonita ciudad que es capital de Vizcaya. Durante aquella breve temporada tuvimos ocasión de estrechar relaciones de afectuosa amistad con una apreciabilísima familia del país, de la cual era miembro la amable persona que tuvo la condescendencia de acompañarnos en todos nuestros paseos y pequeñas excursiones, desempeñando con admirable inteligencia el cargo de cicerone. Una hermosa tarde de agosto me hallaba con ella en la antigua Plaza Mayor — hoy del Mercado-...» (Gómez de Avellaneda, 2008a: 61). La citada cicerone introduce la leyenda: «...sentémonos, por tanto, si V. gusta, y prepare su cartera de viaje para tomar notas del trágico suceso que tuvo lugar en este mismo paraje...» (2008a: 63). En La ondina del lago azul hallamos un comienzo similar: «Era el año de 1859, y tocaba a su término la temporada veraniega — que habíamos pasado en los Pirineos franceses- por lo cual aprovechábamos con avidez los serenos días que aún restaban de la buena estación para proseguir nuestras agradables excursiones por tan pintoresco país» (2008c: 115). El transmisor de esta historia es Lorenzo, guía en la excursión al lago azul: «Sí, aún no habíamos visto el lago azul, y resolvimos aquella excursión postrera en compañía de algunos otros bañistas, que nos presentaron por cicerone al inteligente Lorenzo, a quien soy deudora de la extraña historia que voy a referir a los benévolos lectores de estas desaliñadas páginas» (2008c: 116).

4 «Vivía no sé en qué tiempo (pues la tradición no lo fija), en uno de los blancos caseríos de las verdes montañas...» (2008b: 91). 
miento de sus progenitores, María debe someterse a su hermano Pedro, diez años menor que ella y heredero definitivo de la riqueza familiar. Gómez de Avellaneda se detiene en perfilar el talante amable y afectuoso de él, mientras subraya la tendencia desabrida y hosca de ella, - sin obviar su hermosura - y, pese a todo, la aparente buena relación entre ambos. ${ }^{5}$ Este último aspecto condiciona el terreno para que el acto cainita resulte sorprendente - si bien el rechazo de María hacia el modelo patriarcal imperante avala su ejecución. El crimen provoca el enajenamiento de la asesina, su muerte y castigo final: convertirse en la dama de Amboto, ánima que vaga y presagia desgracias.

\section{LO FEMENINO Y LO FANTÁSTICO COMO DISCURSOS SUBVERSIVOS DE LA RAZÓN ILUSTRADA}

Con el fin de comprender e interpretar en su complejidad una obra como «La dama de Amboto», hasta ahora menos atendida que el resto de su prosa (Selimov, 2001: 109; Simón Palmer, 2015), este trabajo debe partir de unas consideraciones generales de la vida y el pensamiento de la escritora. Ciertamente, podemos afirmar que Gómez de Avellaneda llevó una vida excepcional nada acorde con su época. La única explicación que la sociedad española y la cubana podían encontrar a su destacable talento e indomable carácter era una distinguida masculinidad que confería seguridad a sus actos y a sus escritos. Como recoge Brígida Pastor, el poeta cubano José Martí encontraba en la fuerza y gravedad de sus versos un espíritu irreductiblemente masculino: «no hay mujer en Gertrudis Gómez de Avellaneda; todo anunciaba en ella un ánimo potente y varonil; su cuerpo era alto y robusto, como su poesía ruda y enérgica...» (2002: 10). Las palabras de Martí ilustran la consideración que tenían sus contemporáneos de nuestra autora y de su obra: su talento correspondía a un talante varonil poco ajustado a la naturaleza de su género. Y no únicamente la calidad de sus escritos, también su carácter crítico y reacio a someterse a las expectativas de su época fueron los que causaron un rechazo no exento de cierta admiración, en España. Las actitudes que adoptó a lo largo de su vida hacia el amor, el matrimonio, la familia, la escritura, dan cuenta de hasta qué punto puede ser considerada un espíritu adelantado a su tiempo.

Como sucede con otros tantos escritores hispánicos del Romanticismo, entre los que destaca el caso de Mariano José de Larra (Alborg, 1992: 217), el pensamiento que subyace en el ejercicio literario de Avellaneda es de notable

5 «Era, además, el joven D. Pedro persona simpática y amabilísima, que merecía en todos conceptos primer lugar en el corazón de María» (2008d: 150). 
raigambre ilustrada. Su defensa de la igualdad entre los sexos y la denuncia política de la esclavitud en su primera novela Sab (1841), donde se establece una analogía entre la situación de las mujeres y los esclavos en Cuba (Tabatadze, 2017) — pues, «como los esclavos, ellas arrastran pacientemente su cadena y bajan la cabeza bajo el yugo de las leyes humanas» (Gómez de Avellaneda, 2007: 270-271)_, muestran el componente social y político que la vincula al pensamiento moderno de la Ilustración. También esto fue motivo de reproche para su familia durante los años que vivió en La Coruña, según cuenta la propia escritora en su Autobiografía (1907): «decían que yo era atea, y la prueba que daban era que leía las obras de Rousseau, y que me habían visto comer manteca en viernes» (Gómez de Avellaneda, 2000). A pesar de este influjo, sin embargo, no dejó nuestra autora de criticar las falacias y errores en que cayeron los pensadores ilustrados bajo el auspicio de la razón. La condición de la mujer es un tema que se repite en la prensa de la época y constituye un debate político y literario trascendental en su siglo; en dicho marco, Gómez de Avellaneda enarboló siempre un discurso feminista que ampliaba los horizontes ideológicos de la Ilustración. Y entendemos, como María C. Albin, que gran parte de su labor literaria y periodística estuvo orientada hacia la superación del modelo patriarcal que propugnaban los pensadores ilustrados (2007).

Aun tratándose de un escritor tardío con respecto a otros ilustrados y a pesar de haber mantenido graves desavenencias con ellos, el ginebrino Jean-Jacques Rousseau fue uno de los filósofos más determinantes del siglo XVIII. Para mostrar de qué forma influyó en la obra de Gómez de Avellaneda nos basaremos en dos piezas clave: el Discurso sobre el origen de la desigualdad entre los hombres (1755) y la novela filosófica Emilio (1762). En ambas, como se constata, el escritor trata de explicar sus consideraciones sobre la naturaleza de los hombres y las dinámicas de la sociedad sirviéndose de «las solas luces de la razón» (Rousseau, 1999). Parte Rousseau de que las desigualdades entre los hombres son producto de las diferencias culturales y políticas entre los pueblos, y, en definitiva, por la particular educación que cada uno de ellos recibe. Todos los hombres, en su diversidad, tienen igual acceso a la razón y derecho a la libertad; así pues, en un posible estadio natural del hombre, todos serían esencialmente iguales. Las injusticias sociales y el sometimiento de unos grupos humanos por otros serían prácticas políticas que no encontrarían sustento en la razón. Es decir, que para Rousseau naturaleza y sociedad se erigen como realidades en conflicto.

Sin duda estas ideas debieron configurar la ideología abolicionista de Gómez de Avellaneda, pero ¿qué lugar ocupa la mujer en el pensamiento de 
Rousseau? En el Libro V de Emilio, el ginebrino se detendrá sobre Sofía, quien fuera la mujer ideal del ciudadano. Si en un principio indica que «en todo cuanto no corresponde al sexo, la mujer es hombre» (Rousseau, 1982: 411), estas diferencias fisiológicas comportarían, para Rousseau, insoslayables diferencias morales. Igualmente, entendería que tales diferencias responden al papel que tanto la naturaleza como la sociedad han reservado para la mujer: las labores del hogar y el cuidado de la familia. De este modo, identificaría los géneros masculino y femenino con un carácter fuerte y otro débil respectivamente, siendo la labor de la mujer «complacer al hombre» (1982: 412). A consecuencia de estas diferencias naturales y sociales, la educación de los hombres y de las mujeres debería diferir con el fin de atender los deberes que a cada uno le corresponden en la sociedad. Rousseau es claro en su posicionamiento: «ellas deben aprender muchas cosas, mas solamente aquellas que les conviene saber» (1982: 419). Es natural que Gómez de Avellaneda dudara del ejercicio de la razón si servía para justificar el sometimiento del género femenino por el masculino. De tal modo que su feminismo se enarbola desde un romanticismo que reclama las pasiones frente a la razón, contra las desigualdades naturales de las mujeres y de los hombres, pero que dialoga constantemente con el mito ilustrado de la emancipación social (Albin, 2007; Selimov, 2001: 111). Como ella misma expuso en su artículo «La dama de gran tono» (1843), la mujer bajo el patriarcado se encontraría desnaturalizada, pues «la exigente sociedad la reclama sin cesar, como el teatro a la actriz que ha contratado» (apud Albin, 2007: 162).

No han faltado estudios sobre el discurso feminista en el pensamiento de Gómez de Avellaneda y, efectivamente, constituye una denuncia fundamental en sus escritos. Su vida entera está cargada de anécdotas y acontecimientos que demuestran un carácter y una voluntad fuera de lo común, sin duda, y quiso de su tiempo que estuviera a la altura de sus ideas; la respuesta, claro está, rara vez fue otra que el rechazo. En este sentido, Pastor ha señalado que uno de los temas más recurrentes en su obra es el de la mujer condenada según los términos de la moral cristiana y limitada en su talento por los prejuicios culturales de su tiempo (2002: 39). En la misma dirección apuntan los análisis de Olga Tabatadze, quien ha señalado la tendencia a representar la feminidad oprimida a través de mujeres-objeto, es decir, únicamente valorados en determinación de sus cualidades materiales o como medio para la consecución de un fin (2017: 337). «La dama de Amboto», la leyenda de origen vasco objeto de nuestro estudio, es prueba de cómo la escritora construyó una identidad femenina en oposición a los prejuicios y normas sociales que rigen 
Europa; por ejemplo, la exclusión de las hijas en el reparto de la herencia en favor del varón. Para ello, como veremos, no solamente se sirve de la trama sino que introduce un discurso marcado ideológicamente a través de la voz de la narradora, uno que marca la distancia diacrónica que existe entre el tiempo de lo narrado y de la narración: «Tal era el espíritu de la época de que hablamos: el sexo menos fuerte era desheredado sin piedad, y muchas veces se condenaba a la perpetua clausura de un monasterio, para que el varonil representante de la casa no tuviera ni aún el cuidado de proporcionarle aceptable colocación o módicos alimentos» (Avellaneda, 2008d: 149-150).

Su compromiso político se trasluce ostensiblemente en dicha cita, pero ahora observaremos los múltiples niveles de interpretación que se pueden proyectar sobre esta obra a partir de su componente fantástico. La pregunta es la siguiente: habiendo practicado casi todos los géneros — poesía, novela, teatro, prensa, autobiografía, epístola, etc.-, ¿es posible tratar de interpretar en términos ideológicos y estratégicos su incursión en el cuento romántico en su modalidad legendaria? David Roas advierte que en la mayoría de leyendas y tradiciones fantásticas el componente sobrenatural constituye el eje principal de la narración, de modo que «se cuentan, más allá de otros intereses (morales, culturales, religiosos), para ofrecer al lector de la narración un hecho sorprendente y, en ocasiones, terrorífico» (2006: 159). Sin embargo, citas como la anterior muestran un claro posicionamiento político en el caso de las leyendas de Gómez de Avellaneda. Nos interesa ahora comprender cómo se funden en nuestra autora el discurso feminista y la narración fantástica. Como bien señala Roas, la literatura fantástica comenzó a gestarse durante la Ilustración, cuando la razón y la ciencia excluyeron lo sobrenatural del horizonte de expectativas de lo real; de este modo, la interpretación neoclásica de los preceptos aristotélicos de verosimilitud y mímesis relegó el componente fantástico en la literatura al tratarse de una transgresión de la racionalidad. Es decir, lo fantástico es una herramienta de subversión de lo real y nos enfrenta a aquello que escapa nuestra comprensión: el concepto romántico de lo sublime y su efecto terrorífico (Roas, 2006: 59).

Por otro lado, ya hemos visto cómo el ejercicio de la razón llevó a Rousseau a considerar necesaria la sumisión del género femenino. Como es natural, la escritora cubana no podía sino rechazar la posibilidad de que tales ideas pudieran estar fundadas en la razón (Albin, 2007: 165). Michel Foucault, en Historia de la locura en la Época Clásica (1961), documenta cómo la histeria ha sido contemplada desde el siglo XVIII como una de las enfermedades mentales propias del género femenino (2018: 433). En cierta manera, podemos deducir 
que las situaciones de estrés en el marco de lo social o las manifestaciones de la más mínima rebeldía en las mujeres siempre se han considerado síntomas, brotes histéricos de un desequilibrio mental. Por ello, feminismo y enajenación están conectados dentro del imaginario patriarcal de Occidente. Del mismo modo, Alexander R. Selimov ha señalado que las contradicciones del personaje y su tendencia melancólica llevan

implícita una caracterización no desprovista de un sentido positivo, basada en la asociación con todas estas aptitudes y virtudes; María se define como un ser espiritualmente superior, de rasgos angélicos y a la vez satánicos, según el formato predominante en la configuración de los héroes románticos (2001: 113).

Así pues, lo fantástico se convierte en el vehículo idóneo del discurso feminista porque, como hemos podido constatar, ambos se erigen como narraciones marginales con respecto de la razón ilustrada y se incardinan perfectamente en el romanticismo hispánico; la subversión de lo real por lo fantástico permite, así mismo, la subversión de los roles sociales por la figura femenina. Lo femenino y lo fantástico: dos realidades emancipadoras y transgresoras de la modernidad racional. Así lo ha señalado Selimov al reconocer en este texto un «Romanticismo subversivo», según el concepto desarrollado por Donald Shaw, que problematiza los estereotipos tradicionales de las ideologías de su época, tanto conservadoras como liberales (2001: 113). Cabría añadir algo más; el origen vasco de la tradición recogida por Gómez de Avellaneda podría ser también significativo. La mitología vasca precristiana, todavía determinante en la configuración identitaria y cultural de la sociedad vasca del siglo XIX, se caracteriza por la predominancia de deidades femeninas, así como por una suerte de matriarcado que afecta a la configuración de las estructuras familiares. Si bien su visita a los Pirineos vascos tuvo una motivación concreta - la grave dolencia de su marido Domingo Verdugo-, la admiración que la cultura vasca despierta en la escritora pudo tener relación con dicha significación mítica y social del género femenino.

Detengámonos ahora sobre el personaje principal de «La dama de Amboto»; a partir de su ambigua caracterización masculina, cargada de contradicciones, y de su particular experiencia familiar podemos encontrar ciertas similitudes biográficas con la propia autora. Basta con contrastar algunos rasgos vitales: María Urraca pierde toda pretensión a la herencia de su padre en el momento en que este tiene un hijo varón en segundas nupcias; tras la muerte del padre, María incurriría en fratricidio para recuperar los derechos sobre 
la herencia, aunque dicho crimen no estaría exento de cierta ambigüedad narrativa. En el marco biográfico de la escritora podemos encontrar, si no los mismos acontecimientos exactamente, ciertas concomitancias temáticas: la temprana muerte del padre, las segundas nupcias de la madre y los hijos nacidos de estas, la exclusión en la herencia por parte de su abuelo materno, etc. Así se corrobora en la biografía de la autora realizada por Carmen Bravo-Villasante (1967). Esto no significa que la lectura del texto deba realizarse bajo parámetros exclusivamente autobiográficos, ni mucho menos, pero sí son cuestiones que deben ser atendidas.

Esta tradición parece haber sido transmitida a la autora por un «joven del país», según afirma en La Época (1857), y ciertos críticos lo han identificado con Sotero Manteli (Charques Gámez, 2013: 74); sin embargo, a partir de una comparación con la versión que este publicara hacia 1869 podemos afirmar que, no coincidiendo en lo más mínimo, esta teoría resulta bastante discutible o requeriría un mayor detenimiento. Si atendemos a la leyenda, se nos presenta lo sucedido en el seno de la familia Urraca, nombre que evoca irremediablemente a cierto personaje histórico que conspiraría en el asesinato de su propio hermano: se trataría de doña Urraca de Zamora, hija de Fernando I de León, envuelta en el asesinato de Sancho II de Castilla a manos de Vellido Delfos durante el asedio de Zamora, en el siglo xI. Con todo, las diferencias entre la figura histórica y el personaje de esta tradición vasca son notables: la primera ordena matar a su hermano para poner fin al asedio de Zamora y restablecer la armonía entre los herederos de Fernando I, mientras que la segunda comete por sí misma el asesinato para recuperar sus derechos sobre la herencia.

Tampoco podemos obviar la trágica figura de lady Macbeth si pensamos en el homicidio y la culpa de María Urraca. Como con la histórica doña Urraca, también en la tragedia de William Shakespeare el asesinato, urdido y alentado por la mujer, será cometido por un personaje masculino —en este caso, su esposo, que dará nombre a la pieza: Macbeth (1623). El escritor romántico Thomas De Quincey, en su ensayo «Sobre los golpes a la puerta de Macbeth» (1823), realizaría una destacable lectura del fenómeno sobrenatural acaecido en la escena tercera del acto II, y que podemos trasladar al texto que nos ocupa. Según su interpretación, la caracterización positiva de la víctima, cuya autoridad responde a un derecho natural y moral, y la corrupción moral que mueve el crimen tienen por consecuencia una desnaturalización de los asesinos. Los golpes en la puerta, en primera instancia símbolo de la culpa ineludible, son interpretados por el inglés como el restablecimiento del orden cósmico: «los pulsos de la vida comienzan a latir de nuevo» en oposición al 
«terrible paréntesis» que había suspendido el orden moral (De Quincey, 2008: 154-155). En el texto de Gómez de Avellaneda este paréntesis o ciclo desnaturalizado se cierra al término de un año, cuando lo fantástico interviene para consumar el destino mortal de María Urraca. El orden moral y cósmico queda, así, restablecido. Sin embargo, aún persisten sombras sobre la verdad tras la muerte del hermano: la narración, como en el texto shakespeariano, no escenifica el crimen, de modo que la locura y la justicia divina aún adolecen de cierta ambigüedad que salva a la fratricida.

Aún podemos añadir algunas notas más antes de comentar aspectos concretos de la narración; el pueblo, contra los otros señores que pretenden enterrar juntamente a los hermanos, se erige en personaje colectivo para destruir en venganza el palacio señorial de los Urraca — acto en el que, por cierto, advertimos ciertas resonancias con el drama de Lope de Vega, Fuenteovejuna (1619). ¿Qué lectura podemos extraer de esto? El hecho de que Gómez de Avellaneda denunciara la sumisión de la mujer en las sociedades occidentales trasluce, en cierto modo, una visión de las costumbres sociales muy próxima a la de Rousseau: dinámicas que corrompen la naturaleza de los hombres y que construyen desigualdades entre ellos. La figura de María Urraca se nos presenta como esencialmente trágica en tanto que la injusticia que sufre en relación con su género la condena al fratricidio; la nobleza mantiene una posición ambigua con respecto al crimen, pero proyecta una interpretación bondadosa de la muerte: es la tristeza y no la culpa lo que enloquece a la dama. Por último, el pueblo, personaje sometido a otro modelo de desigualdad — socioeconómica, pero también divina—, se convierte en el actante que restaura la moral tradicional, el orden cósmico.

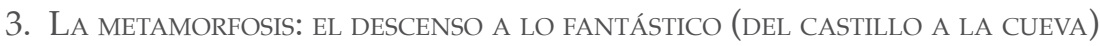

A continuación, el foco de nuestro interés se detendrá sobre los procesos de metamorfosis que tienen lugar en «La dama de Amboto», y cómo estos determinan la inserción de lo fantástico en dicha leyenda. María Urraca deriva en la diosa Mari. En la tradición mitológica vasca destacan las figuras femeninas y, de ellas, Mari se alza como matriarca. Hablamos, pues, de una mitología matriarcal, con una Gran Diosa que perfilamos siguiendo a José Miguel Barandiarán (1979), Andrés Ortiz-Osés (2007) y Jon Mentxakatorre Odriozola (2017). Ofrecemos tres rasgos característicos de Mari de los que, consideramos, se hace eco Gómez de Avellaneda en su tradición vasca, demostrando así la atención que la escritora concede al mito. 
En primer lugar, debemos señalar que Mari es una divinidad símbolo del ámbito telúrico y habitante del subsuelo. Por ello, no parece casual la anexión de María Urraca a la tierra. El monte y la peña, reiterados en la apertura y cierre del texto, resultan espacios clave en la vida y metamorfosis del personaje. Allí se encuentra el castillo (Gómez de Avellaneda, 2008d: 149), espacio de intimidad de la familia Urraca; desde allí se precipitan los dos hermanos al abismo con un año de diferencia (2008d: 154) y precisamente es este acontecimiento el que otorga nombre a la conocida peña del País Vasco:

Desde entonces la peña que corona el monte Echaguen —en que aquel [castillo] existió - fue llamada Amboto, que significa — traducido literalmente- allí arrojar; porque en el vascuence casi no se conoce de los verbos sino el infinitivo. Atendiendo a ello, la palabra Amboto tiene su verdadera versión en la frase: de allí fue arrojada (2008d: 155).

La tradición expuesta por Gómez de Avellaneda refleja la transición de María Urraca, habitante de un castillo, a Mari, moradora en una cueva. Se trata de un viaje de catábasis en el que nos movemos en entornos de intimidad, reserva y seguridad. Como apunta Bachelard (2006: 210) en La tierra y las ensoñaciones del reposo, toda gruta resulta un espacio propicio para la imaginación y, a la vez, un perímetro que el individuo siente predisposición a ocupar. La cueva es intimidad y silencio; pero también ambiente de trabajo y comunicación con uno mismo. María Urraca desea heredar el castillo familiar — que recibe tras el asesinato de su hermano-. Este «ensueño delirante que constituyó su martirio» (Gómez de Avellaneda, 2008d: 152) resulta un mero tránsito hasta su propia morada: la cueva desde la que se expresa con autenticidad ofreciendo respuestas a quienes consultan; el verdadero hogar desde el que organiza las tormentas y del que ella misma decide cuándo salir. Es en la libertad de esa cueva que habla a gritos, parafraseando a Víctor Hugo en La leyenda de los siglos (1859), donde María Urraca alcanza su libertad y verdadera identidad.

Esta transición del castillo a la cueva resulta inversa a la esperada naturalmente: de algún modo nos descoloca y nos permite definirla como reflejo de la progresiva entrada del lector al plano fantástico (Todorov, 1981: 124). En este sentido, no podemos obviar que el interés de Gómez de Avellaneda por el germen realista de la historia supera su desenlace mágico; apenas alude al elemento sobrenatural en los dos párrafos finales del texto:

...Desde entonces, añade también la tradición, el alma de la fratricida vaga errante por las hondas entrañas del abismo, saliendo solo para anunciar desastres. 
Los días en que la cumbre de la montaña aparece envuelta en densos nubarrones, los pastores retiran sus rebaños, los labriegos se acogen al caserío abandonando las campestres faenas y los marineros se guardan bien de dejar el puerto para confiarse a las olas porque es fama que por tales signos se conoce que la dama de Amboto se ha escapado de su tumba y anda por ahí, presagiando desgracias (Gómez de Avellaneda, 2008d: 155).

La relación personaje-elemento telúrico refleja también la conexión de Mari con la agricultura, como recuerda Hartsuaga (apud Mentxakatorre, 2017: 10). Mentxakatorre (2017: 11), siguiendo a Caro Baroja y a Sorazu, establece una vinculación, atendiendo a lo telúrico, entre Mari y Proserpina. Desde nuestro punto de vista y, teniendo presente su vinculación con la agricultura, Mari también se emparenta con la madre de la reina del inframundo: Ceres. Cabría hablar de una especie de fusión entre madre e hija grecorromanas y la figura mítica vasca. Si extendemos esta idea al germen del mito, en «La dama de Amboto», Gómez de Avellaneda introduce un detalle llamativo: tanto la muerte de Pedro como la de María tienen lugar en otoño, ${ }^{6}$ estación en la que Proserpina abandona la superficie terrestre y regresa con su esposo mientras Ceres cubre los campos de tristeza hasta su retorno en primavera.

De acuerdo con Arana y Hartsuaga, Mari conecta con el elemento aéreo además de con la tierra: se reproduce en el aire y se asocia a los fenómenos meteorológicos (apud Mentxakatorre, 2017: 9-10). Junto a la propensión romántica por los soberbios temporales, tanto el fratricidio cometido por Mari como su propio deceso ocurren en noches de tormenta. Gómez de Avellaneda expone prolijamente la primera tempestad:

El firmamento se cubre de negros nubarrones, que envuelven en sus densos pliegues las cimas de las montañas; cruzan entre ellas los relámpagos como serpientes de fuego; resiembran árboles al rudo impulso del viento silbador; retumba pavoroso el trueno por los montes y los valles y todos huyen despavoridos, buscando albergue que los defienda de aquellas iras del cielo (2008d: 151).

Y, sobre la segunda tormenta, apunta que «La tempestad bramaba como en la horrenda noche de la catástrofe» (2008d: 154). Pero no solo es posible vincular a Urraca con temporales físicos: el propio personaje encarna la cualidad de refulgir como un relámpago. El día en el que salen de caza, el cuerpo de María actúa a imitación de una señal luminosa, alertando de una

6 «Lucía serena una mañana de otoño, cuando los sones de las cornamusas y trompetas anunciaron a los habitantes del valle la salida de los ilustres cazadores...» (Gómez de Avellaneda, 2008d: 150). 
novedad: «Tiempo hacia que no brillaba en el perfecto semblante de la noble doncella la viva animación que entonces hermoseaba; pero al admirarla, no era posible dejar de sentir que había algo de febril en la mirada fulgurante de sus grandes ojos pardos» (2008d: 151). Igualmente, la noche de su muerte observamos su «lívida frente, que ilumina un relámpago» (2008d: 154). La propia María Urraca encarna y refleja elementos tempestuosos, como corresponde a la que será la deidad del tiempo atmosférico.

Como último rasgo característico de Mari debemos añadir que la deidad es capaz de adoptar multitud de formas, de ejecutar numerosas acciones y de ofrecer respuesta a las consultas planteadas por los humanos a modo de oráculo (Mentxakatorre, 2017: 10-11). Ella modifica su apariencia y es activa física y mentalmente. Así mismo, con anterioridad a su metamorfosis, Urraca, «gallardísima y virtuosa», como apunta Gómez de Avellaneda (2008d: 150), exhibe su lozanía física a lo largo del texto y logra, durante la jornada de caza, ejecutar la hazaña más llamativa: herir con la diestra un jabalí (2008d: 151). Un personaje poderoso destinado a convertirse en un ser proteico, hábil y de honda inteligencia capaz de valerse por sí mismo. Advertimos, en el fondo, la sombra de otra mujer: la de la propia escritora.

\section{CONCLUSIONES}

En conclusión, los aspectos tratados en este trabajo nos permiten interpretar «La dama de Amboto» como un ejercicio de construcción literaria por el cual, aunque dentro de los márgenes temáticos de la tradición vasca, Gertrudis Gómez de Avellaneda integra un discurso feminista en el universo sobrenatural de lo fantástico. María Urraca, una vez cumplido el ciclo vital que parte desde su presentación hasta su muerte, por fin queda liberada de todas las dinámicas sociales que la sometían y la encadenaban. Es castigada por su crimen, pero la muerte termina por ser la salvación de su espíritu y la integración en un mundo regido por leyes sobrenaturales; un mundo desvinculado de las leyes humanas y donde no existe la desigualdad social porque se encuentra fuera de los límites de lo posible. La cueva mágica, en oposición al castillo cristiano, se convierte en un espacio simbólico de resistencia contra lo real, contra la razón y la civilización patriarcal. La literatura fantástica es un refugio para la mujer feminista porque la libera de las responsabilidades sociales, porque le permite abandonar indefinidamente el limitado mundo de los hombres. 
BiBLIOGRAFÍA

Albin, María C. (2007): «El costumbrismo feminista de Gertrudis Gómez de Avellaneda», Anales de Literatura Hispanoamericana, núm. 36, pp. 159-170.

Alborg, Juan Luis (1992): Historia de la literatura española. El Romanticismo, tomo IV, Gredos, Madrid.

BACHELARD, Gaston (2006): La tierra y las ensoñaciones del reposo. Ensayo sobre las imágenes de la intimidad, trad. Rafael Seuovia, Fondo de Cultura Económico, México D.F.

BARANDiARÁn, José Miguel de (1979): Mitología vasca, Txertoa, San Sebastián.

Bravo-Villasante, Carmen (1967): Una vida romántica. La Avellaneda, Edhasa, Barcelona.

Charques Gámez, Rocío (2013): «Lo culto y lo popular en las tradiciones vascas y pirenaicas de Gertrudis Gómez de Avellaneda», en D. Thion Soriano-Mollá, L. Beltrán Almería y S. Hibbs (eds.), Tradición e interculturalidad: las relaciones entre lo culto y lo popular (siglos XIX y XX), Institución Fernando el Católico, Zaragoza, pp. 69-79.

De QuinceY, Thomas (2008): Del asesinato considerado como una de las Bellas Artes y otros ensayos literarios, trad. José Rafael Hernández Arias, Valdemar, Madrid.

Ezama GiL, Ángeles (2011): «Los relatos de viajes de Gertrudis Gómez de Avellaneda», Anales, núm. 23, pp. 323-351.

FERNÁNDEZ, Teodosio (2014): «De pasiones imaginarias: la narrativa de Gertrudis Gómez de Avellaneda», Arbor, núm. 770, p. 11.

Foucault, Michel (2018): Historia de la locura en la Época Clásica I, trad. Juan José Utrilla, Fondo de Cultura Económica, México D.F.

Gómez de Avellaneda, Gertrudis (2000): Autobiografía y cartas (hasta ahora inéditas) de la ilustre poetisa Gertrudis Gómez de Avellaneda, Biblioteca Virtual Miguel de Cervantes, Alicante, disponible en http://www.cervantesvirtual.com/nd/ ark:/59851/ bmcbc3w7. [Fecha de consulta: 20 de junio de 2020]

- (2007): Sab, ed. José Servera, Cátedra, Madrid.

- (2008a): La bella toda y Los doce jabalíes: dos tradiciones de la Plaza del Mercado de Bilbao, Biblioteca Virtual Miguel de Cervantes, Alicante, disponible en http:/ / www. cervantesvirtual.com/nd/ark:/59851/bmcpg1r1. [Fecha de consulta: 20 de junio de 2020]

— (2008b): La flor del ángel: tradición vascongada, Biblioteca Virtual Miguel de Cervantes, Alicante, disponible en http://www.cervantesvirtual.com/nd/ark:/59851/ bmcf1902. [Fecha de consulta: 20 de junio de 2020]

-(2008c): La ordina del lago azul: recuerdo de mi última excursión por los Pirineos, Biblioteca Virtual Miguel de Cervantes, Alicante, disponible en http: / www.cervantesvirtual.com/nd/ark:/59851/bmc98881. [Fecha de consulta: 20 de junio de 2020]

—(2008d): La dama de Amboto: tradición vasca, Biblioteca Virtual Miguel de Cervantes, Alicante, disponible en http://www.cervantesvirtual.com/nd/ark:/59851/ bmc5h7h8. [Fecha de consulta: 20 de junio de 2020]

Mentzakatorre Odriozola, Jon (2017): «La dama de Amboto y el infierno. Mito y fórmula», Revista de Folklore, núm. 430, pp. 4-34. 
ORTIZ-OsÉs, Andrés (2007): Los mitos vascos: aproximación hermenéutica, Universidad de Deusto, Bilbao.

Pastor, Beatriz (2002): El discurso de Gertrudis Gómez de Avellaneda: identidad femenina y otredad, Universitat d'Alacant, Alicante.

RoAs, David (2006): De la maravilla al horror. Los inicios de lo fantástico en la cultura española (1750-1860), Mirabel, Pontevedra.

Rousseau, Jean-Jacques (1982): Emilio, trad. Luis Aguirre Prado, Edaf, Madrid.

- (1999): Discurso sobre la desigualdad de los hombres, trad. Ángel Pumarega, Biblioteca Virtual Miguel de Cervantes, Alicante, disponible en http:/ / www.cervantesvirtual.com/nd/ark:/59851/bmc89137. [Fecha de consulta: 20 de junio de 2020]

Selimov, Alexander R. (2001): «Tradición y subversión en la prosa de Gertrudis Gómez de Avellaneda», Romance Notes, núm. 42 (1), pp. 107-114.

Simón PALmer, María del Carmen (2015): «Estudios sobre Gertrudis Gómez de Avellaneda (1980-2014)», Rassegna iberistica, núm. 104, pp. 325-340.

TABAtadze, Olga (2017): «Esclavos y libres en la novela Sab de Gertrudis Gómez de Avellaneda», Anales de Literatura Hispanoamericana, núm. 46, pp. 335-348.

Todorov, Tzvetan (1981): Introducción a la literatura fantástica, trad. Silvia Delpy, Premia Editora, México D.F. 